\title{
Range sizes of groundwater amphipods (Crustacea) are not smaller than range sizes of surface amphipods: a case study from Iran
}

\author{
Somayeh Esmaeili-Rineh \\ Department of Biology, Faculty of Science, Razi University, Bagabrisham 6714967346, \\ Kermanshah, Iran \\ sesmaeili@razi.ac.ir
}

Mahmoud Mamaghani-Shishvan

Department of Biology, Faculty of Science, Razi University, Bagabrisham 6714967346, Kermanshah, Iran

\section{Cene Fišer}

Department of Biology, Biotechnical Faculty, University of Ljubljana, Večna pot 111, SI-10oo Ljubljana, Slovenia

\section{Vahid Akmali}

Department of Biology, Faculty of Science, Razi University, Bagabrisham 6714967346, Kermanshah, Iran

\section{Nargess Najafi}

Department of Biology, Faculty of Science, Razi University, Bagabrisham 6714967346, Kermanshah, Iran

\footnotetext{
Abstract

The connectivity of groundwater aquifers is lower compared to surface waters. Consequently, groundwater species are expected to have smaller distributional ranges than their surface relatives. Molecular taxonomy, however, unveiled that many species comprise complexes of morphologically cryptic species, with geographically restricted distributional ranges in subterranean as well as in surface waters. Hence, the range sizes of surface and groundwater species might be more similar in size than hitherto thought. We tested this hypothesis by comparing the range size of surface amphipods of the genus Gammarus and subterranean amphipods of the genus Niphargus in Iran. We re-analyzed the taxonomic structure of both genera using two unilocus species delimitation methods applied to a fragment of the COI mitochondrial marker, to identify molecular operational taxonomic units (MOTUs), and assessed the 
maximum linear extent (MLE) of the ranges of MOTUs from both genera. Genus Gammarus comprised 44-58 MOTUs while genus Niphargus comprised 20-22 MOTUs. The MLEs of the two genera were not significantly different, regardless the delimitation method applied. The results remained unchanged also after exclusion of single site MOTUs. We tentatively conclude that in this case there is no evidence to consider that groundwater species are geographically more restricted than surface species.

\section{Keywords}

Gammarus - Iran - mitochondrial and nuclear genes - Niphargus - range size - species delimitation

\section{Introduction}

The groundwater is the largest reservoir of unfrozen freshwater in the World (Gibert \& Deharveng, 2002). Despite that, groundwater metazoans count less than $10 \%$ of the global metazoan species richness (Gibert \& Deharveng, 2002), suggesting that specific ecological conditions such as a permanent darkness, limiting food and reduced short-term climatic fluctuations (Culver \& Pipan, 2009), act as a strong abiotic filter. Few taxa nevertheless successfully colonized and diversified in the groundwater (Trontelj, 2018), and nowadays represent some of the ecologically most specialized freshwater organisms and some of the oldest freshwater inhabitants (Humphreys, 2000; Culver \& Pipan, 2009; Protas \& Jeffery, 2012; Mammola, 2019).

Subterranean aquatic species have generally narrow distributional ranges, presumably due to the high degree of fragmentation of groundwater aquifers (Trontelj et al., 2009; Zagmajster et al., 2014; Delić et al., 2017; Eme et al., 2017). Species with large ranges are an exception (Eme et al., 2014; Copilaș-Ciocianu et al., 2017), and seemingly more common in northern latitudes (Zagmajster et al., 2014; Eme et al., 2017). Such narrow range-endemic species are generally considered as an important fraction of the global natural heritage. Their presence may steer nature-conservation decisions on a local and regional scale (Sket, 1999;
Chapman et al., 2009). In comparison, surface habitats are better connected, the dispersal of surface species is less limited and these species have presumably larger distributional ranges (Cardoso, 2012; Altermatt et al., 2014; Alther et al., 2016). The differences in the within-surface and within-subterranean habitat connectivity and putative differences in range sizes imply a hypothesis that the subterranean fauna is on average more endangered and should be monitored more carefully than the surface fauna.

The hypothesis that subterranean species are geographically more restricted (endemic) and potentially more threatened than surface species, so far received little attention (but see Cardoso, 2012; Mammola et al., 2019), and remains to be tested for aquatic fauna. Over the past decades it has become clear that a substantial fraction of species diversity can be identified only with the help of molecular methods (Bickford et al., 2007; Fišer et al., 2018). Morphologically identical or highly similar species, so-called cryptic species, are common in all animal phyla and can be expected in all regions of the world (Pfenninger \& Schwenk, 2007; Pérez-Ponce de León \& Poulin, 2016). Many studies unveiled that also geographically widespread surface species in fact comprise complexes of narrow endemic species (Copilaş-Ciocianu \& Petrusek, 2015; Mamos et al., 2016), thereby suggesting that the degree of endemism in surface waters may Downloaded from Brill.com04/26/2023 09:39:07AM 
be underestimated and that the difference in endemism between surface and groundwater animals is less distinct than previously thought.

Here we test this hypothesis using surface and subterranean amphipods from the genera Gammarus Fabricius, 1775 and Niphargus Schiödte, 1849 from Iran. Gammarus is the largest amphipod genus in surface freshwater of the World, living mainly in springs, rivers and lakes around the Holarctics (Väinölä et al., 2008; Hou et al., 2011; Hou \& Sket, 2015). Genus Niphargus can be considered as its subterranean counterpart, the largest amphipod genus in groundwater, living in the Western Palearctics (Väinölä et al., 2008; Fišer, 2012). Cryptic diversity in both genera is well documented (Trontelj et al., 2009; Meleg et al., 2013; Altermatt et al., 2014; Copilaş-Ciocianu \& Petrusek, 2015; Mamos et al., 2016). In Iran, both genera were sampled and examined using molecular methods (Esmaeili-Rineh et al., 2015, 2017b; Katouzian et al., 2016; Mamaghani-Shishvan et al., 2017), and can be used for testing whether ranges of subterranean species are smaller than ranges of surface species.

We assembled genetic and distributional data on genera Niphargus and Gammarus from Iran. Several samples of Niphargus from Azerbaijan province in Iran have been collected for the first time. To test our hypothesis, we applied genetic species delimitation methods to standardize taxonomic units, and defined range sizes as the maximum linear extent (MLE) between the two distant-most points.

\section{Material and methods}

\section{The data collection}

The samples were derived from various collections. Data for the genus Gammarus (supplementary table $\mathrm{S} 1$ ) were extracted from the database published in Katouzian et al. (2016).
The total dataset comprised 67 localities in the Irano-Anatolian and Caucasus area, and 180 COI sequences which yielded 104 haplotypes.

Data for the genus Niphargus (supplementary table S2) comprised new data and published ones. The new collections were made by the second author in April-September 2016. Other niphargid data were supplied by published data in Esmaeili-Rineh et al. (2015) and Mamaghani-Shishvan et al. (2017). The total dataset comprised 44 ( 35 old, 9 new) localities, 72 individuals (49 old, 23 new) and 46 COI haplotypes ( 33 old, 13 new). For this study we sequenced also $28 \mathrm{~s}$ rDNA fragment; from 79 individuals ( 56 old, 23 new) we obtained 46 haplotypes (33 old, 13 new). All localities are shown in fig. 1.

\section{Phylogenetic analyses of the new samples}

We extracted the total genomic DNA from pleon using Tissue Kits $\left(\mathrm{GenNet}^{\mathrm{Bio}}{ }^{\mathrm{m}}\right)$ following the manufacturer's instructions (Seoul, South Korea). Mitochondrial COI was amplified using the modified primer pair LCO149oJJ and HCO2198-JJ (Astrin \& Stüben, 2008). Amplification and sequencing of the first fragment of $28 \mathrm{~S}$ ribosomal DNA ( $\mathrm{rDNA}$ ) were performed using the forward primer developed by Verovnik et al. (2005) and the reverse primer used by Zakšek et al. (2007). Each $25 \mu \mathrm{l}$ reaction consisted of optimized amounts of PCR water, $12.5 \mu \mathrm{l}$ of Master Mix kit (Sinaclon, Iran), $0.2 \mu \mathrm{l}$ of each primer $(10 \mu \mathrm{M})$, and 50-100 ng of genomic DNA template. For COI gene amplification, an initial denaturation step at $94^{\circ} \mathrm{C}$ for 3 minutes was followed by 36 cycles of 40 seconds at $94^{\circ} \mathrm{C}, 40$ seconds at $52.5^{\circ} \mathrm{C}$ and 2 minutes at $65^{\circ} \mathrm{C}$ with a final extension step for 8 minutes at $65^{\circ} \mathrm{C}$. Cycling parameters for the $28 \mathrm{~S}$ rDNA gene were as follows: initial denaturation of $94^{\circ} \mathrm{C}$ for $7 \mathrm{~min}$ utes, 35 subsequent cycles of $94^{\circ} \mathrm{C}$ for 45 seconds, $55^{\circ} \mathrm{C}$ for 30 seconds, $72^{\circ} \mathrm{C}$ for 1 minute, and a final extension of $72^{\circ} \mathrm{C}$ for 7 minutes. Purification of PCR products and sequencing Down loaded from Brill. come4/26/2623 09:39:87 


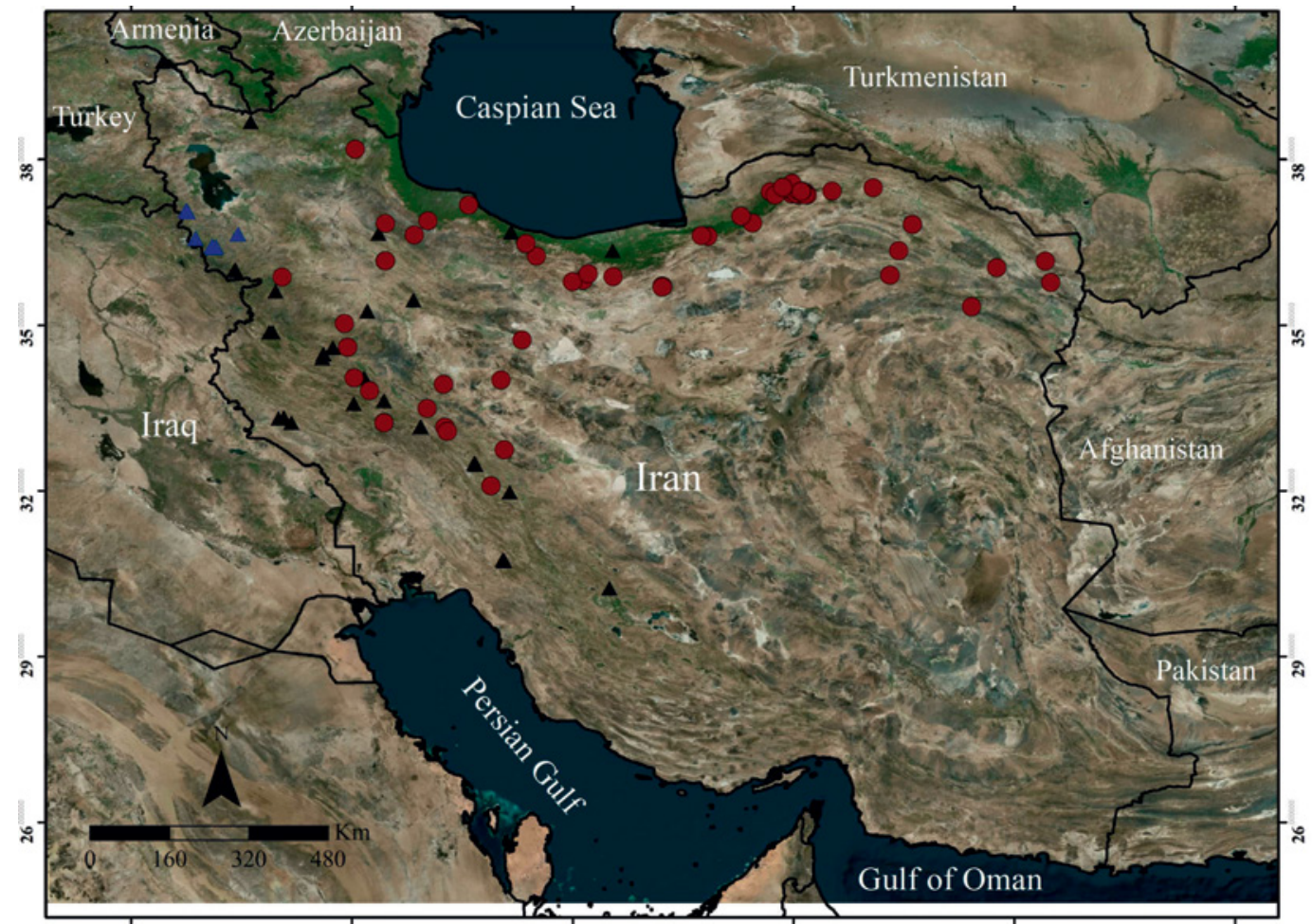

FIGURE 1 Distribution map of analyzed gammarid and niphargid species from Iran. Red circles show gammarid distribution records. Black triangles show previous niphargid distributions. Blue triangles show new distribution of Niphargus populations in this study.

were commercially performed by Macrogen Inc. (Korea). Sequencing was performed with both primers mentioned above.

In order to identify the phylogenetic position of the newly sequenced samples (with GenBank accession numbers $\mathrm{MN}_{496474}$ to MN496491 and MN502676 to MN502693), they were analyzed within the data set of EsmaeiliRinehetal.(2015,2017b). MostofIranian species were from a monophyletic clade (EsmaeiliRineh et al., 2015). We selected three species as an outgroup, Niphargus aquilex Schiödte, 1855, Niphargus krameri Schellenberg, 1935 and Niphargus schellenbergi S. Karaman, 1932, whose sequences are available at NCBI (accession numbers: EF617264, JF420841; EF617274, $\mathrm{KF}_{719253}$ and EU693321, JF420854). All sequences were edited and aligned using ClustalW(Thompson etal.,1994), as implemented in the Bioedit program sequence alignment editor(Hall,1999) using the default settings.

Phylogenetic reconstruction was performed using Bayesian inference in Mr Bayes, version 3.1.2 (Ronquist \& Huelsenbeck, 2003). Analyses were run for five million generations, with four chains, and the trees were sampled every 1000 generations under GTR $+\mathrm{G}$ and GTR + I + G models (jModelTest, version 0.1.1, Posada 2008) for $28 \mathrm{~S}$ and COI genes, respectively. The first 1250 sampled trees were discarded as burn-in, and the subsequent tree likelihoods were checked for convergence in Tracer 1.5.0 (Rambaut \& Drummond, 2009). A fifty percent majority rule consensus tree was computed using the remaining trees and visualized by FigTree v1.4.o software. The data on analyzed species are available in supplementary tables $S_{1}$ and $S_{2}$. 


\section{Species delimitation methods}

We applied two molecular species delimitation approaches, namely Automatic Barcode Gap Discovery (ABGD), Bayesian Poisson Tree Process (bPTP) methods (Puillandre et al., 2012; Zhang et al., 2013). The same methods and settings were used as in previous studies of genus Gammarus populations (Katouzian et al., 2016), which we re-used in the analyses of genus Niphargus populations as follows.

The ABGD delimitation was run using the following settings: the parameter range of $\mathrm{P}_{\text {min }}=0.001, \mathrm{P}_{\text {max }}=0.10$, gap width $=0.8-1.1$, and a Kimura-2-parameter $\left(\mathrm{K}_{2} \mathrm{P}\right)$ model (Kimura, 1980) corrected genetic distance matrix generated in MEGA ver. 5 (Tamura et al., 2011). In bPTP species delimitation were performed using the webserver (http://www .species.h-its.org) and default settings. As input, we used a COI tree produced with BEAST v1.7.4. The input file for BEAST was produced in BEAUTi v.1.7. The settings were as follows: 50 million generations, sampling each 5000 th tree, standard coalescent model, GTR + I + $G$ substitution model with four gamma categories and a strict clock. GTR + I + G model was proposed by model selection in jModel test. Appropriateness of parameters (effective sample size >20o) was tested with Tracer vi.6. Results were visualized with Tree Annotator v1.7.4 with a $10 \%$ burn-in rate, posterior probability of 0.9 and under the maximum clade credibility option for the consensus tree.

For five Niphargus species we had only $28 \mathrm{~S}$ sequences, and previous studies proved to be genetically and morphologically distinct from other Niphargus species (Hekmatara et al., 2013; Esmaeili-Rineh et al., 2016, 2017a, 2018). These species, however, are known from single sites and could be unambiguously included into the dataset.

\section{Distributions}

The maximum linear extents (MLE) for molecularly delimited operational units were obtained in ArcGIS (version 10.2). Species, known from a single locality were arbitrarily assigned a distributional range of $1 \mathrm{~km}$. The distribution of MLE was left skewed and not normal, hence we tested whether ranges of surface and subterranean species differed in sizes using the nonparametric MannyWhitney U test using IBM SPSS 20.

\section{Results}

The genus Gammarus comprised five morphospecies (G. komareki, G. lacustris, G. lordeganensis, G. balcanicus and G. hegmatanensis). These counted 44 and $5^{8}$ putative cryptic species (hereafter molecular operational taxonomic units, MOTUs), delimited using ABGD and bPTP, respectively (see also Katouzian et al., 2016). The MLEs of genus Gammarus MOTUs measured between 1 and $831 \mathrm{~km}$, regardless the delimitation method.

The genus Niphargus counted 16 described species and several putative new species which are pending further taxonomic work. New samples from west Azerbaijan province comprised two strongly supported subclades, both nested in the main Iranian clade (fig. 2). The ABGD and bPTP species delimitations suggested that the samples collected from west Azerbaijan province comprised 8 and 9 species, respectively (fig. 3; supplementary table S2). All known samples of genus Niphargus counted 24 and 26 MOTUs, according to ABGD and bPTP delimitations, respectively. The MLEs of genus Niphargus MOTUs ranges measured between 1 and $644 \mathrm{~km}$ and between 1 and $844 \mathrm{~km}$, when we used bPTP and ABGD delimitations, respectively.

Overall, species ranges of surface species were not larger than distributions of subterranean species neither for MOTUs delimited using ABGD (MannWhitney U test, $\mathrm{p}=\mathbf{0 . 4 8 9}$ ) nor for MOTUs delimited using bPTP (MannWhitney U test, $\mathrm{p}=0.191)$. Many MOTUs are 


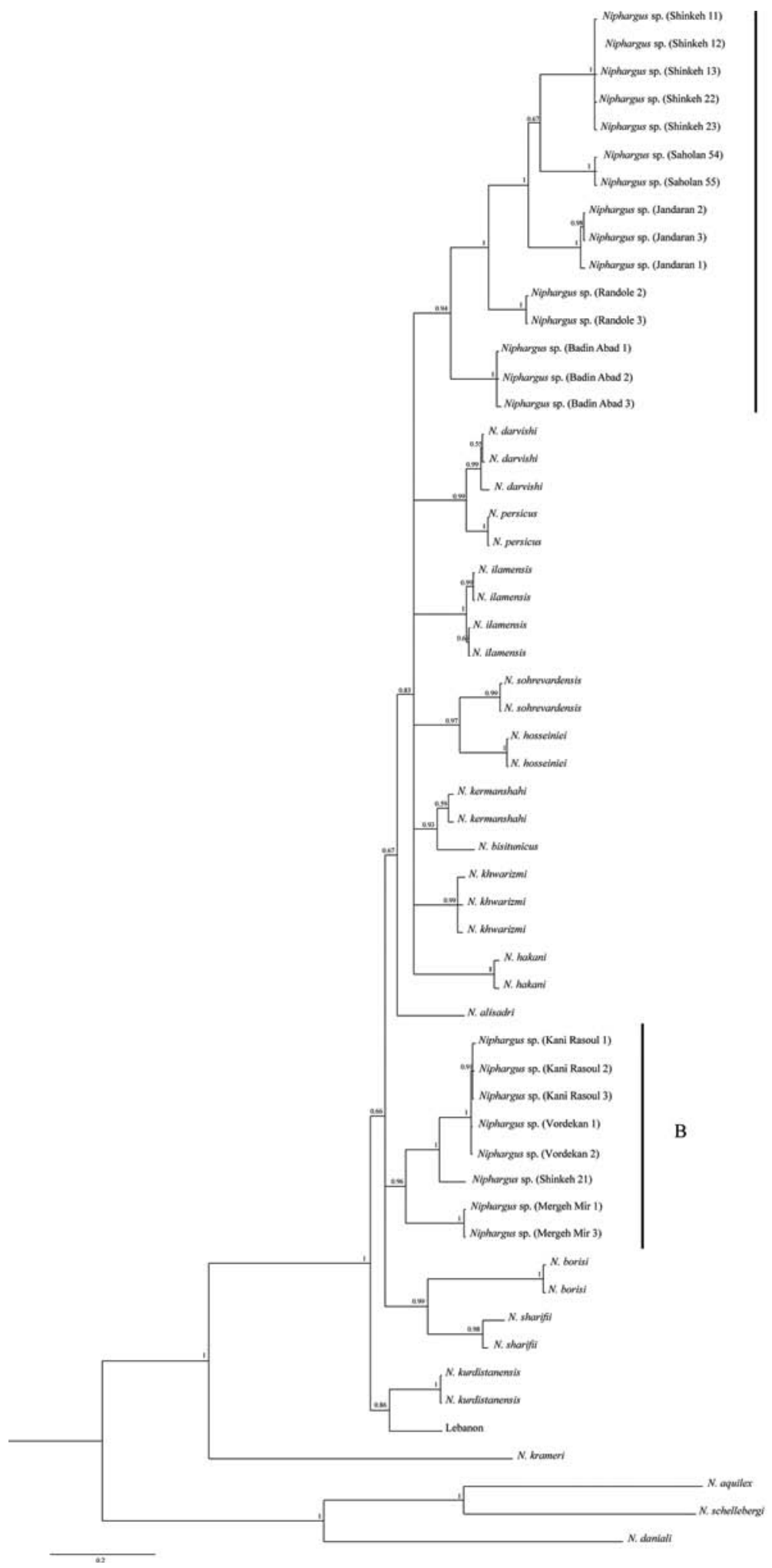

FIGURE 2 Bayesian tree of 54 specimens as inferred from the $28 \mathrm{~S}$ and COI gene sequences. All specimens were collected from Iran, new samples fall into two unsupported clades dabelled as elade A and B.6Xumbers 39 : 07AM above line indicate the Bayesian posterior probabilities. 


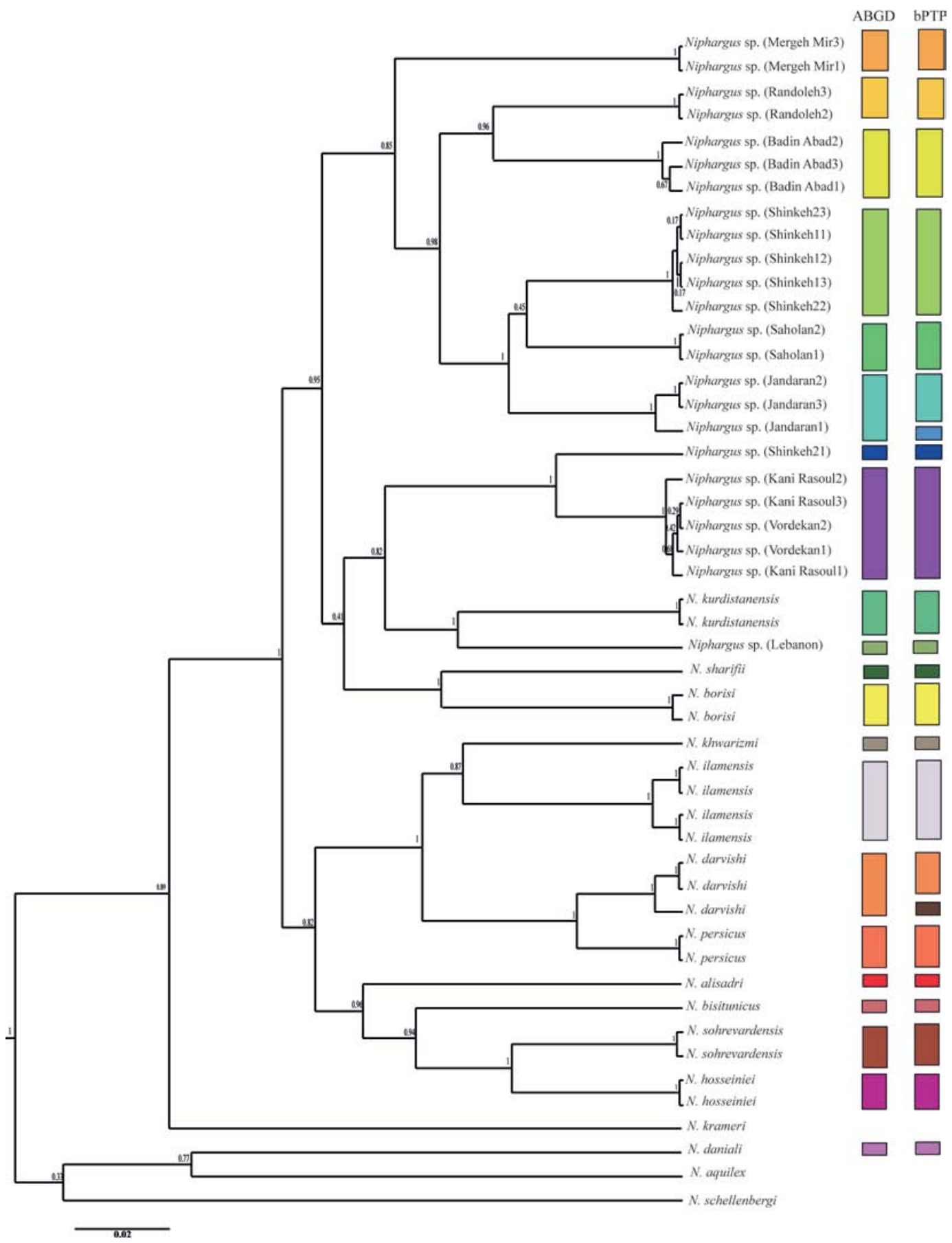

FIGURE 3 Species delimitations of new Niphargus populations. The figure shows the BEAST tree as inferred from COI gene sequences. Putative species, as a result of species delineation using bPTP and ABGD, are indicated with side bars. Please note that the figure does not contain five additional species for which we did not have COI sequences, known from a single locality, which proved to be morphologically and genetically distinct according to the more conservative $28 \mathrm{~S}$ gene marker. New samples are presented in boldface. 

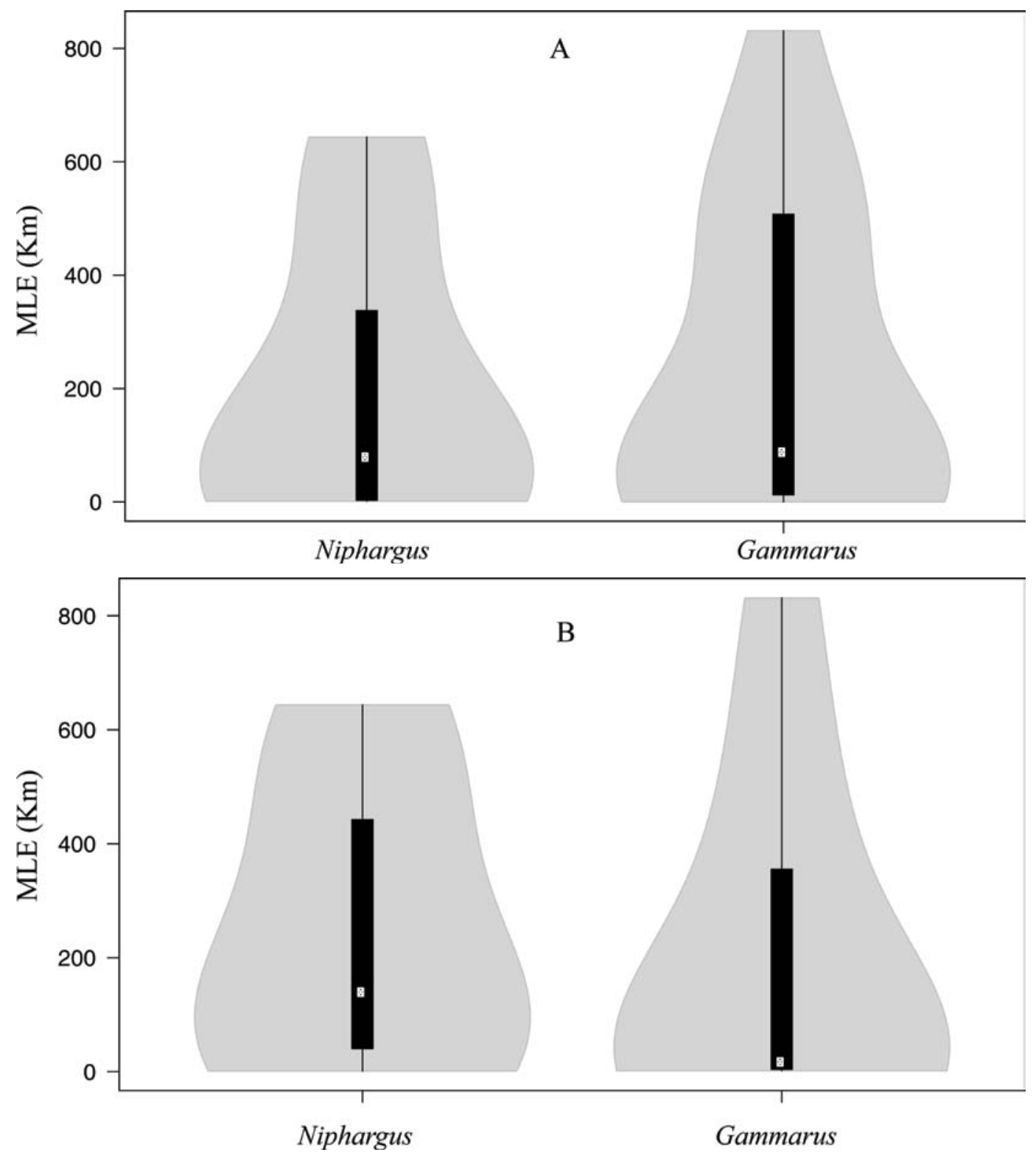

FIGURE 4 Violin plots, representing maximum linear extent for Gammarus and Niphargus species delimited using $\operatorname{ABGD}(\mathrm{A})$ and $\mathrm{bPTP}(\mathrm{B})$. The white dot in the middle indicates the median value in the range size, the thick black bar in the center represents the interquartile range and the thin black line shows $95 \%$ of all data. The distributions of surface species are not larger than the distributions of subterranean species (Mann-Whitney U test, $\mathrm{p}=0.794(\mathrm{~A}), \mathrm{p}=0.837(\mathrm{~B})$ ). MOTUs found on a single localities are excluded.

known from only one locality for both surface genus Gammarus (ABGD / bPTP : 31 / 45) and subterranean genus Niphargus (ABGD/bPTP : 16 / 20). Given that MOTUs known from a single site may indicate incomplete sampling, we repeated the analyses by exclusion of single-site species. In this dataset, the number of localities per Gammarus species is between 2-8 (ABGD, 13 MOTUs) or between 2-4 (bPTP, 13 MOTUs), whereas the number of localities 
per Niphargus species is between 2-3 (ABGD, 8 MOTUs and bPTP, 6 MOTUs; note that bPTP produced many more single-site MOTUs). The results, however, remained unchanged (MannWhitney U tests: $\mathrm{p}=0.794$ (ABGD) and $\mathrm{p}=0.837$ (bPTP), fig. 4).

\section{Discussion}

The results of our study did not support the hypothesis that subterranean species have smaller distributional ranges than surface species and that they should be treated as more endangered per se. While the connectivity of surface amphipod populations within a single catchment is not problematic, the connectivity between catchments seems to be as challenging as the connectivity between groundwater aquifers. Amphipods carry their eggs in the marsupium and do not have desiccation resistant propagules (e.g., Kaestner, 1970), which might explain their relatively limited range sizes among surface species. By contrast, the groundwater aquifers may temporarily communicate through occasional subterranean connections, occurring at high water levels that at least temporary enhance the subterranean connectivity (Palandačić et al., 2012; Konec et al., 2016). Despite that small ranges are the rule in groundwater (Trontelj et al., 2009), in continuous karst areas, some species apparently can establish and maintain large distributional ranges using subterranean connections that do not reflect hydrological conditions on the surface (Lefebure et al., 2006; Delić et al., 2017; Zakšek et al., 2018). Our results suggest that range sizes of surface and subterranean amphipod species should be revised in general. This conclusion is in accord with a recent review of cryptic diversity of the amphipod crustaceans (Fišer et al., 2018). The meta-analysis of studies suggested that cryptic amphipod species were found in all studied families, and from all environmental conditions, including surface and subterranean freshwater, semi-terrestrial, marine pelagial and benthos, deep sea and parasites. Virtually all these studies showed that distributional ranges of molecularly delimited species are much smaller than distributional ranges of morphologically defined species (Fišer et al., 2018).

The conclusions, however, should be considered with some care. We foresee three possible caveats that advise a caution in interpretation and application of these results. First, low number of samples per species implies sampling deficiency. In our sampling scheme we detected common species with the largest ranges, and single-site endemics. If the sampling was not sufficient, species with small ranges cannot be told apart from species with small to medium sized ranges. The species with small to mid-sized ranges might modify frequency distributions of range sizes, and if the frequency distributions of surface species changed differently from frequency distributions of subterranean species, the conclusions might change. Addressing this caveat would require additional sampling, ideally using a standardized monitoring scheme to control for the sampling effort and false negative records.

The second issue is that the sampling regions do not entirely overlap. The ranges increase with the latitude, a phenomenon known as Rappaport effect (Zagmajster et al., 2014; Hof et al., 2008). Sampling of genus Gammarus populations was on average more intense in different mountain massifs, lying in northern latitudes (fig. 1) than sampling of genus Niphargus populations. Unfortunately, the number of adequately sampled species is not high enough to appropriately model the variation of range size taking into account geographic latitude and the ecological character of species. This omission, however, is less like given that the studied region covers 
only approximately 10 degrees of latitude, and that the region was not strongly influenced by Quaternary glaciations.

The third issue is that our analysis compares only amphipod crustaceans. The results cannot be applied to other animal groups directly, given the differences in biology among animal taxa, especially their capacities of locomotion and dispersal ecology. Any generalizations of these results need to be made with care.

We recognize that the above caveats cannot be resolved within this study, hence the results of our study need to be considered only as preliminary. We, however, find it interesting that the development of molecular methods and different quantifications of biodiversity, challenged the longstanding paradigm of subterranean endemism. Systematic research in different countries and using different taxa is needed to resolve the issue.

\section{Acknowledgments}

This project was funded by the Iran National Science Foundation (INSF-96005707). This study was supported by Razi University as a part of the MSc thesis of the second author. CF was funded by Slovenian Research Agency, Program P1-0184. Our special thank goes to Stefano Mammola, Charles Oliver Coleman and an anonymous reviewer whose constructive comments substantially improved the manuscript.

\section{Supplementary material}

Supplementary material is available online at: https://doi.org/10.6o84/mg.figshare.9692738

\section{References}

Altermatt, F., Alther, R., Fišer, C., Jokela, J., Konec, M., Kuery, D., Maechler, E., Stucki, P. \&
Westram, A.M. (2014) Diversity and distribution of freshwater amphipod species in Switzerland (Crustacea: Amphipoda). PLoS ONE, 9, el10328. doi:10.1371/journal.pone.0110328

Alther, R., Fišer, C. \& Altermatt, F. (2016) Description of a widely distributed but overlooked amphipod species in the European Alps. Zool. J. Linn. Soc., 179, 751-766.

Astrin, J.J. \& Stüben, P.E. (2008) Phylogeny in cryptic weevils: molecules, morphology and new genera of western Palaearctic Cryptorhynchinae (Coleoptera: Curculionidae). Invertebr. Syst., 22, 503-522. doi:10.1071/is07057

Bickford, D., Lohman, D.J., Sodhi, N.S., Ng, P.K.L., Meier, R., Winker, K., Ingram, K.K. \& Das, I. (2007) Cryptic species as a window on diversity and conservation. Trends Ecol. Evol., 22, 148-155. doi:10.1016/j.tree.2006.11.004

Cardoso, P. (2012) Diversity and community assembly patterns of epigean vs. troglobiont spiders in the Iberian Peninsula. Int. J. Speleol., 41, 83-94.

Chapman, M.G., Underwood, A.J. \& Clarke, K.R. (2009) New indices for ranking conservation sites using "relative endemism". Biol. Conserv., 142, 3154-3162. doi:10.1016/j.biocon.2009.08.017

Copilaș-Ciocianu, D., Fišer, C., Borza, P., Balazs, G., Angyal, D. \& Petrusek, A. (2017) Low intraspecific genetic divergence and weak niche differentiation despite wide ranges and extensive sympatry in two epigean Niphargus species (Crustacea: Amphipoda). Zool. J. Linn. Soc., 181, 485-499. doi: 10.1093/zoolinnean/zlwo31

Copilaş-Ciocianu, D. \& Petrusek, A. (2015) The southwestern Carpathians as an ancient centre of diversity of freshwater gammarid amphipods: insights from the Gammarus fossarum species complex. Mol. Ecol., 24, 3980-3992. doi:10.1111/mec.13286

Culver, D.C. \& Pipan, T. (2009) The Biology of Caves and Other subterranean Habitats, ist ed. Oxford University Press, New York.

Delić, T., Trontelj, P., Rendoš, M. \& Fišer, C. (2017) The importance of naming cryptic species and the conservation of endemic subterranean Downloaded from Brill.com04/26/2023 09:39:07AM 
amphipods. Sci. Rep., 7, 3391. doi:10.1038/s41598017-02938-z

Delić, T., Švara, V., Coleman, C.O., Trontelj, P. \& Fišer, C. (2017) The giant cryptic amphipod species of the subterranean genus Niphargus (Crustacea, Amphipoda). Zool. Scr., 46, 740-752. Eme, D., Malard, F., Colson-Proch, C., Jean, P., Calvignac, S., Konecny-Dupré, L., Hervant, F. \& Douady, C.J. (2014) Integrating phylogeography, physiology and habitat modelling to explore species range determinants. J. Biogeogr., 41, 687-699. doi:10.1111/jbi.12237

Eme, D., Zagmajster, M., Delić, T., Fišer, C., Flot, J-F., Konecny-Dupré, L., Pálsson, S., Stoch, F., Zakšek, V., Douady, C.J., Malard, F., Konecny-Dupre, L., Palsson, S., Stoch, F., Zakšek, V., Douady, C.J. \& Malard, F. (2017) Do cryptic species matter in macroecology? sequencing European groundwater crustaceans yields smaller ranges but does not challenge biodiversity determinants. Ecography, 41, 1-13. doi:10.1111/ecog.02683

Esmaeili-Rineh, S., Sari, A., Delić, T., Moškrič, A. \& Fišer, C. (2015) Molecular phylogeny of the subterranean genus Niphargus (Crustacea: Amphipoda) in the Middle East: a comparison with European niphargids. Zool.J. Linn. Soc., 175, 812-826.

Esmaeili-Rineh, S., Heidari, F., Fišer, C. \& Akmali, V. (2016) Description of new endemic species of the genus Niphargus Schiödte, 1849 (Amphipoda: Niphargidae) from a karst spring in Zagros Mountains in Iran. Zootaxa, 4126, 338-350. doi:10.11646/zootaxa.4126.3.2.

Esmaeili-Rineh, S., Mirghaffari, S.A. \& Sharifi, M. (2017a) The description of a new species of Niphargus from Iran based on morphological and molecular data. Subterr. Biol. 22, 43-58.

Esmaeili-Rineh, S., Sari, A., Fišer, C. \& Bargrizaneh, Z. (2017b) Completion of molecular taxonomy: description of four amphipod species (Crustacea: Amphipoda: Niphargidae) from Iran and release of database for morphological taxonomy. Zool.Anz., 271,57-79.doi:10.1016/j.jcz.2017.04.0o9 Esmaeili-Rineh, S., Mohammad Niakan, A. \& Akmali, V. (2018) Niphargus sarii sp. n., a new subterranean niphargid (Crustacea: Amphipoda) from Iran based on molecular and morphological characters. Acta zool. Acad. Sci. Hung., 64, 113-132. doi:10.17109/AZH.64.2.113.2018

Fabricius, J.C. (1775) Systema entomologiae sistens insectorum classes, ordines, genera, species, adjectis synonymis, locis, descriptionibus, observationibus, i-xv, 1-832. (Flensburgi et Lipsiae).

Fišer, C. (2012) Niphargus: A model system for evolution and ecology. In: W.B. White \& D.C. Culver (eds) Encyclopedia of Caves, pp. 555-564. Academic Press. doi:10.1016/B978-0-12-3838322.00082-7

Fišer, C., Robinson, C.T. \& Malard, F. (2018) Cryptic species as a window into the paradigm shift of the species concept. Mol. Ecol., 27, 613-635. doi:10.1111/ijlh.12426

Gibert, J. \& Deharveng, L. (2002) Subterranean ecosystems: a truncated functional biodiversity. BioScience, 52, 3-81. doi:10.1641/00o6-3568(2002) 052[0473:SEATFB]2.0.CO;2

Hall, T.A. (1999) BioEdit: a user-friendly biological sequence alignment editor and analysis program for Windows 95/98/NT. Nucleic Acids Symp. Ser., 41, 95-98.

Hekmatara, M., Zakšek, V., Heidari, M.B. \& Fišer, C. (2013) Two new species of Niphargus (Crustacea: Amphipoda) from Iran. J. Nat. Hist., 47, 1421-1449. doi:10.1080/00222933.2012.743616

Hof, C., Brändle, M. \& Brandl, R. (2008) Latitudinal variation of diversity in European freshwater animals is not concordant across habitat types. Glob. Ecol. Biogeogr., 17, 539-546.

Hou, Z. \& Sket, B. (2015) A review of Gammaridae (Crustacea: Amphipoda): the family extent, its evolutionary history, and taxonomic redefinition of genera. Zool. J. Linn. Soc., 176, 323-348. doi:10.1111/zoj.12318

Hou, Z., Sket, B., Fišer, C. \& Li, S. (2011) Eocene habitat shift from saline to freshwater promoted Tethyan amphipod diversification. Proc. Natl. Acad. Sci. U. S. A., 108, 14533-14538. doi:10.1073/ pnas.1104636108

Humphreys, W.F. (2000) Relict faunas and their derivation. In: H. Wilkens, D.C. Culver \& W.F. Downloaded from Brill.com04/26/2023 09:39:07AM via free access 
Humphreys (Eds) Ecosystems of the World: Subterranean Ecosystems, pp. 417-432. Elsevier, Amsterdam.

Kaestner, A. (1970) Crustacea. Invertebrate Zoology. John Wiley and Sons, Inc., New York.

Katouzian, A-R., Sari. A., Macher, J.N, Weiss, M., Saboori, A., Leese, F. \& Weigand, A.M. (2016) Drastic underestimation of amphipod biodiversity in the endangered Irano-Anatolian and Caucasus biodiversity hotspots. Sci. Rep., 6, 22507. doi:10.1038/srep22507

Kimura, M. (1980) A simple method for estimating evolutionary rate of base substitutions through comparative studies of nucleotide sequences. J. Mol. Evol., 16, 111-120.

Konec, M., Delić, T. \& Trontelj, P.(2016) DNA barcoding sheds light on hidden subterranean boundary between Adriatic and Danubian drainage basins. Ecohydrology, 9, 1304-1312.

Lefébure, T., Douady, C.J., Gouy, M., Trontelj, P., Briolay, J. \& Gibert, J. (2006) Molecular phylogeography of Niphargus virei. Mol. Ecol., 15, 1797-1806.

Mamaghani-Shishvan, M., Esmaeili-Rineh, S. \& Fiser, C. (2017) An integrated morphological and molecular approach to a new species description of amphipods in the Niphargidae from two caves in west of Iran.J. zool. stud., 56, 1-20.

Mammola, S. (2019) Finding answers in the dark: caves as models in ecology fifty years after Poulson and White. Ecography, 42, 1331-1351. doi:10.1111/ecog.03905

Mammola, S., Piano, E., Malard, F., Vernon, P. \& Isaia, M. (2019) Extending Janzen's hypothesis to temperate regions: a test using subterranean ecosystems. Func. Ecol. doi:10.1111/1365-2435.13382 Mamos, T., Wattier, R., Burzyński, A. \& Grabowski, M. (2016) The legacy of a vanished sea: a high level of diversification within a European freshwater amphipod species complex driven by 15 My of Paratethys regression. Mol. Ecol., 25, 795810. doi:10.1111/mec.13499

Meleg, I.N., Zakšek, V., Fišer, C., Kelemen, B.S. \& Moldovan, O.T. (2013) Can environment predict cryptic diversity? The case of Niphargus inhabiting Western Carpathian groundwater. PLoS ONE, 8, e76760. doi:10.1371/journal.pone .0076760

Palandačić, A., Matschiner, M., Zupančič, P. \& Snoj, A. (2012) Fish migrate underground: the example of Delminichthys adspersus (Cyprinidae). Mol. Ecol., 21, 1658-1671. doi:10.1111/j.1365 -294 X.2012.05507

Pérez-Ponce de León, G. \& Poulin, R. (2016) Taxonomic distribution of cryptic diversity among metazoans: not so homogeneous after all. Biol. Lett., 12, 20160371. doi:10.1098/rsbl.2016.0371

Pfenninger, M. \& Schwenk, K. (2007) Cryptic animal species are homogeneously distributed among taxa and biogeographical regions. $B M C$ Evol. Biol., 7, 121. doi:10.1186/1471-2148-7-121

Posada, D. (2008) jModelTest: phylogenetic model averaging. Mol. Biol. Evol., 25, 1253-1256.

Protas, M. \& Jeffery, W.R. (2012) Evolution and development in cave animals: from fish to crustaceans. WIREs Dev. Biol., 1, 823-845. doi:10.1002/ wdev.61

Puillandre, N., Lambert, A., Brouillet, S. \& Achaz, G. (2012) ABGD, automatic barcode gap discovery for primary species delimitation. Mol. Ecol., 21, 1864-1877. doi:10.1111/j.1365-294X.2011.05239.X

Rambaut, A. \& Drummond, A.J. (2009) Bayesian Evolutionary Analysis Sampling Trees (BEAST). Version 1.7.4.

Ronquist, F. \& Huelsenbeck, J.P. (2003) MrBayes 3: Bayesian phylogenetic inference under mixed models. Bioinformatics, 19, 1572-1574.

Schiödte, J.G. (1849) Bidrag til den underjordiske fauna: det kong danske vidensk Selsk krifter Femte Raekke Naturv Mathem Afd Andet Bind. Copenhagen. 2, $39 \mathrm{p}$.

Sket, B. (1999) The nature of biodiversity in hypogean waters and how it is endangered. Biodivers. Conserv., 8, 1319-1338. doi:10.1023/A:1008916601121 Tamura, K., Peterson, D., Peterson, N., Stecher, G., Nei, M. \& Kumar, S. (2011) MEGA5: Molecular Evolutionary Genetics Analysis using maximum likelihood, evolutionary distance, and 
maximum parsimony methods. Mol. Biol. Evol., 28, 2731-2739.

Thompson, J.D., Higgins, D.G. \& Gibson, T. (1994) Clustal W: improving the sensitivity of progressive multiple sequence alignment through sequence weighting, position specific gap penalties and weight matrix choice. Nucleic Acids Res., 22, 4673-4680.

Trontelj, P., Douady, C.J., Fišer, C., Gibert, J., Gorički, Š., Lefébure, T., Sket, B. \& Zakšek, V. (2009) A molecular test for cryptic diversity in ground water: how large are the ranges of macro-stygobionts? Freshwater Biol., 54, 727-744. doi:10.1111/j.1365-2427.2007.01877.x

Trontelj, P. (2018) Structure and genetics of cave populations. In: O. Moldovan, L. Kovač \& S. Halse (eds) Cave Ecology (Series Ecological Studies - Analyses and Synthesis), pp. 269-298. Springer.

Väinölä, R., Witt, J.D.S., Grabowski, M., Bradbury, J.H., Jazdzewski, K. \& Sket, B. (2008) Global diversity of amphipods (Amphipoda; Crustacea) in freshwater. Hydrobiologia, 595, 241-255. doi:10.1007/s10750-007-9020-6

Verovnik, R., Sket, B. \& Trontelj, P. (2005) The colonization of Europe by the freshwater crustacean Asellus aquaticus (Crustacea: Isopoda) proceeded from ancient refugia and was directed by habitat connectivity. Mol. Ecol., 14, 4355-4369.

Zagmajster, M., Eme, D., Fišer, C., Galassi, D., Marmonier, P., Stoch, F., Cornu, J.F. \& Malard, F. (2014) Geographic variation in range size and beta diversity of groundwater crustaceans: insights from habitats with low thermal seasonality. Glob. Ecol. Biogeogr., 23, 1135-1145. doi:10.1111/ geb.12200

Zakšek, V., Sket, B. \& Trontelj, P. (2007) Phylogeny of the cave shrimp Troglocaris: evidence of a young connection between Balkans and Caucasus. Mol. Phylogenetics Evol., 42, 223-235.

Zakšek, V., Delić, T., Fišer, C., Jalžić, B. \& Trontelj, P. (2018) Emergence of sympatry in a radiation of subterranean amphipods. J. Biogeogr., 46, 657-669.

Zhang, J., Kapli, P., Pavlidis, P. \& Stamatakis, A. (2013) A general species delimitation method with applications to phylogenetic placements. Bioinformatics, 29, 2869-2876. doi:10.1093/bio informatics/btt499

RECEIVED: 20 JUNE 2019 | REVISED AND ACCEPTED: 20 AUGUST 2019

EDITOR: R. VONK 